\title{
Erratum to: Clinical and radiographical results after double flip button stabilization of acute grade III and IV acromioclavicular joint separations
}

\author{
Michael C. Glanzmann • Stefan Buchmann • \\ Laurent Audigé $\cdot$ Christoph Kolling $\cdot$ Matthias Flury
}

Published online: 29 October 2013

(C) Springer-Verlag Berlin Heidelberg 2013

\section{Erratum to: Arch Orthop Trauma Surg}

DOI 10.1007/s00402-013-1858-7

The original version of this article unfortunately contained a mistake. The affiliation of the second and third author is incorrect. The correct affiliation for second and third author is:

S. Buchmann

Klinikum Rechts der Isar, Abteilung für Sportorthopädie, Munich, Germany

L. Audigé

Orthopädie Obere Extremitäten, Schulthess Klinik Zurich, Zurich, Switzerland

The online version of the original article can be found under doi:10.1007/s00402-013-1858-7.

M. C. Glanzmann $(\bowtie) \cdot$ L. Audigé · C. Kolling · M. Flury Orthopädie Obere Extremitäten, Schulthess Klinik Zurich, Lengghalde 2, 8008 Zurich, Switzerland

e-mail:mcglanzmann@sunrise.ch

S. Buchmann

Klinikum Rechts der Isar, Abteilung für Sportorthopädie,

Munich, Germany 